\title{
Capacidade embriogênica da cultivar IAS-5 de soja(1)
}

\begin{abstract}
Antonio Orlando Di Mauro(2), Roberto Carlos de Oliveira ${ }^{(2)}$ e João Ademir de Oliveira ${ }^{(2)}$
Resumo - O objetivo deste trabalho foi estudar o controle genético da formação de embriões somáticos da cultivar IAS-5 de soja. O experimento foi conduzido em casa de vegetação, cultivando-se quatro plantas por vaso, sob fotoperíodo de 14 horas e temperatura em torno de $28^{\circ} \mathrm{C}$. Efetuaram-se cruzamentos entre os parentais não-embriogênicos (cultivares IAC-6, Paraná e IAC-15) e embriogênico (cultivar IAS-5) e retrocruzamentos para obtenção das gerações $\mathrm{F}_{1}, \mathrm{~F}_{2}, \mathrm{RC}_{1} \mathrm{P}_{1}$ e $\mathrm{RC}_{1} \mathrm{P}_{2}$. Cotilédones imaturos, com 4-6 mm de comprimento, derivados dos parentais das gerações $F_{1}, F_{2}, R_{1} P_{1}$ e $R_{1} P_{2}$ foram cultivados em placas de Petri contendo meio N10, por um período de 90 dias, em câmara de crescimento. Os embriões somáticos derivados da indução foram contados, e os números, usados para obtenção dos parâmetros genéticos. Os resultados obtidos mostraram que o caráter capacidade de produção de embriões somáticos da cultivar IAS-5 é de natureza quantitativa e controlado por, aproximadamente, 20 genes.
\end{abstract}

Termos para indexação: Glycine max, embrião somático, hibridação, herança genética, controle genético.

\section{Embryogenic capability of cultivar IAS-5 of soybean}

\begin{abstract}
The objective of this work was to study the genetic control of somatic embryo formation on cultivar IAS-5 of soybean. The experiment was carried out in a greenhouse, where four plants per pot were grown under a photoperiod of 14 hours at a temperature about $28^{\circ} \mathrm{C}$. Several crosses between non-embryogenic parental lines (cultivars IAC-6, Paraná and IAC-15) and embryogenic parental line (cultivar IAS-5) and backcrosses to obtain $\mathrm{F}_{1}, \mathrm{~F}_{2}, \mathrm{RC}_{1} \mathrm{P}_{1}$ and $\mathrm{RC}_{1} \mathrm{P}_{2}$ generations were performed. Immature cotyledons, with 4-6 mm in length, derived from parental lines and from $F_{1}, F_{2}, R_{1} P_{1}$ and $\mathrm{RC}_{1} \mathrm{P}_{2}$ generations were grown for 90 days in Petri dishes containing the inductive N10 medium, in a growth chamber. The number of somatic embryos derived from induction was used to estimate genetic parameters. The results showed that somatic embryogenesis capability of cultivar IAS-5 is of quantitative nature and is controlled by twenty genes approximately.
\end{abstract}

Index terms: Glycine max, somatic embryos, hybridization, genetic inheritance, genetic control.

\section{Introdução}

A soja é uma das principais oleaginosas produzidas no mundo e matéria-prima empregada na elaboração de diversos produtos, desde óleo até papel. Em função de seu valor econômico e de sua potencialidade de cultivo em diferentes condições, essa leguminosa tem sido submetida a um intenso programa de melhoramento genético e ambiental.

(1) Aceito para publicação em 8 de novembro de 2000 .

(2) Universidade Estadual Paulista, Faculdade de Ciências Agrárias e Veterinárias, Dep. de Produção Vegetal, CEP 14870-000 Jaboticabal, SP. E-mail: orlando@fcav.unesp.br, jaoliv@fcav.unesp.br, rcoliveira@netsite.com.br
Hiromoto \& Vello (1986) destacam que a base genética da soja é bastante estreita, ou seja, a maioria dos genótipos disponíveis para cultivo derivam de ancestrais comuns, e devido a isso, os programas convencionais de melhoramento têm sido pouco eficientes, e resultaram em progressos genéticos não muito significativos. Dessa maneira, espera-se, com a biotecnologia, obter ganhos genéticos mais expressivos.

O desenvolvimento de métodos eficientes para a regeneração de plantas de soja in vitro amplia as oportunidades para a manipulação genética e para seleção de novos genótipos. Além disso, aumenta a perspectiva de uma nova fonte de variabilidade, a variação somaclonal, que pode contribuir para a ampliação da base genética da soja. 
Estudos preliminares relativos à herança da capacidade embriogênica em soja evidenciaram que tal característica é de natureza quantitativa (Di Mauro et al., 1995b). Bodanese-Zanettini et al. (1993) mostraram que ocorre grande influência do genótipo na capacidade de as cultivares de soja sofrerem embriogênese somática. Os mesmos autores reportaram a boa capacidade embriogênica da cultivar IAS-5.

Objetivou-se neste trabalho estudar o controle genético da formação de embriões somáticos na soja, cultivar IAS-5.

\section{Material e Métodos}

Os experimentos foram conduzidos em casa de vegetação e no Laboratório de Biotecnologia Aplicada ao Melhoramento de Plantas, da Faculdade de Ciências Agrárias e Veterinárias, Unesp, Câmpus de Jaboticabal. Em casa de vegetação foram cultivadas quatro plantas por vaso sob fotoperíodo de 14 horas e temperatura em torno de $28^{\circ} \mathrm{C}$. Foram efetuados os cruzamentos entre o parental embriogênico IAS-5 e os parentais não-embriogênicos IAC-6, Paraná e IAC-15. Foram obtidas vagens derivadas de autofecundações $\left(\mathrm{P}_{1}, \mathrm{P}_{2}\right.$ e $\left.\mathrm{F}_{2}\right)$, de cruzamentos $\left(\mathrm{F}_{1}\right)$, e dos retrocruzamentos $\left(\mathrm{RC}_{1} \mathrm{P}_{1}\right.$ e $\left.\mathrm{RC}_{1} \mathrm{P}_{2}\right)$. As vagens contendo os cotilédones imaturos com 4-6 mm de comprimento foram coletadas, identificadas e transportadas para o laboratório, onde foram submetidas ao processo de assepsia, segundo o método utilizado e descrito por Di Mauro et al. (1995a, 1995b). Na capela de fluxo laminar, os cotilédones foram depositados em placas de Petri contendo o meio de cultura indutor N10, observando-se as recomendações de Di Mauro et al. (1994).

As placas contendo os cotilédones foram incubadas em câmara de crescimento, sob intensidade luminosa de 27-33 $\mu \mathrm{E} \mathrm{m}^{-2} \mathrm{~s}^{-1}$, temperatura de $26 \pm 2^{\circ} \mathrm{C}$, e regime fotoperiódico de 23 horas de luz/1 hora de escuro. A cada 15 dias os cotilédones foram transferidos para um novo meio de cultura N10, por um período de 90 dias.

Os dados oriundos das contagens dos embriões somáticos produzidos pelas gerações parentais $\left(\mathrm{P}_{1}\right.$ e $\left.\mathrm{P}_{2}\right)$, $\mathrm{F}_{1}, \mathrm{~F}_{2}, \mathrm{RC}_{1} \mathrm{P}_{1}$ e $\mathrm{RC}_{1} \mathrm{P}_{2}$ foram empregados para os estudos relacionados com a genética da embriogênese somática em soja. Médias, variâncias e erros-padrões foram estimados de acordo com Kilen (1989), como segue:

$\hat{\mu}=\sum_{i=1}^{k} f_{i} x_{i} / \sum_{i=1}^{k} f_{i}$, em que:

$\hat{\mu} \stackrel{i=1}{=}$ média;

$\sum_{i=1}^{k} f_{i} x_{i}=$ somatório dos produtos da freqüência pelo valor observado, até a k-ésima mensuração, e $\sum_{i}^{k} f_{i}=$ somatório das freqüências.

$\hat{\sigma}^{2}=\left(\sum_{i=1}^{k} f_{i} x_{i}{ }^{2}-\sum_{i=1}^{k} f_{i} \mu^{2}\right) / \sum_{i=1}^{k} f_{i}$, em que:

$\hat{\sigma}^{2}=$ variância;

$\sum_{i=1}^{k} f_{i} x_{i}{ }^{2}=$ somatório dos produtos da freqüência pelo quadrado do valor observado até a k-ésima mensuração, e $\sum_{i=1}^{k} f_{i} \mu^{2}=$ somatório dos produtos da freqüência pelo quadrado da média, até a k-ésima mensuração.

$s(\hat{m})=\hat{\sigma} / \sqrt{\mathrm{N}}$, em que:

$s(\hat{m})=$ erro-padrão;

$\hat{\sigma}=$ desvio-padrão e

$\sqrt{\mathrm{N}}=$ raiz quadrada do tamanho da amostra.

As esperanças das gerações $F_{1}, F_{2}$ e dos retrocruzamentos $\left(\mathrm{RC}_{1} \mathrm{P}_{1}\right.$ e $\left.\mathrm{RC}_{1} \mathrm{P}_{2}\right)$ foram estimadas como segue:

$\mathrm{E}\left(F_{1}\right)=\left[\mu_{1} \mathrm{P}_{1} / \mathrm{NP}_{1}+\mu \mathrm{P}_{2} / \mathrm{NP}_{2}\right] / 2 \times \mathrm{N} F_{1}$, em que:

$\mu \mathrm{P}_{1}$ e $\mu \mathrm{P}_{2}=$ média dos parentais 1 e 2 , respectivamente;

$\mathrm{NP}_{1}=$ tamanho da amostra do parental 1;

$\mathrm{NP}_{2}=$ tamanho da amostra do parental $2 \mathrm{e}$

$\mathrm{N} F_{1}=$ tamanho da amostra da geração $\mathrm{F}_{1}$.

$\mathrm{E}\left(F_{2}\right)=\left[\mu F_{1} / \mathrm{N} F_{1}+\mathrm{E}\left(F_{1}\right) / \mathrm{N} F_{1}\right] 2 \times \mathrm{N} F_{2}$, em que:

$\mu F_{1}=$ média da geração $\mathrm{F}_{1} \mathrm{e}$

$\mathrm{N} F_{2}=$ tamanho da amostra da geração $\mathrm{F}_{2}$.

$\mathrm{E}\left(R C_{1} \mathrm{P}_{1}\right)=\left[3 / 4 \mu \mathrm{P}_{1} / \mathrm{NP}_{1}+1 / 4 \mu \mathrm{P}_{2} / \mathrm{NP}_{2}\right] \times \mathrm{N} R C_{1} \mathrm{P}_{1}$, em que:

$\mathrm{N} R C_{1} \mathrm{P}_{1}=$ tamanho da amostra do cruzamento entre a geração $\mathrm{F}_{1}$ e o parental $\mathrm{P}_{1}$.

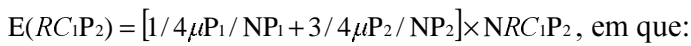

$\mathrm{N} R C_{1} \mathrm{P}_{2}=$ tamanho da amostra do cruzamento entre a geração $\mathrm{F}_{1}$ e o parental $\mathrm{P}_{2}$.

Salienta-se que no cálculo das esperanças, a multiplicação pelo tamanho da amostra $(\mathrm{N})$ nas diversas gerações foi necessária como fator de correção dos diferentes números de cotilédones observados em cada geração.

Fundamentado nas proposições de Allard (1974), Fehr (1987), Falconer (1989), Ramalho et al. (1989), Vencovsky \& Barriga (1992) e Ramalho et al. (1993), foram obtidas estimativas genéticas, como segue: $\hat{\sigma}^{2}=2 \hat{\sigma}_{F 2}^{2}-\left(\hat{\sigma}_{R C I P 1}^{2}+\hat{\sigma}_{R C 1 P 2}^{2}\right)$, em que: $\hat{\sigma}_{\mathrm{A}}^{2}=$ variância genética aditiva;

$\hat{\sigma}_{F 2}^{2}=$ variância fenotípica da geração $\mathrm{F}_{2}$;

$\hat{\sigma}_{R C 1 P 1}^{2}=$ variância fenotípica do cruzamento entre a geração $\mathrm{F}_{1}$ e o parental 1 , e

$\hat{\sigma}_{R C 1 P 2}^{2}=$ variância fenotípica do cruzamento entre a geração $\mathrm{F}_{1}$ e o parental 2.

$\hat{\sigma}^{2} \mathrm{E}=\left(\hat{\sigma}_{\mathrm{P} 1}^{2}+\hat{\sigma}_{\mathrm{P} 2}^{2}+\hat{\sigma}_{\mathrm{F} 1}^{2}\right) / 3$, em que:

$\hat{\sigma}^{2}=$ variância ambiental;

$\hat{\sigma}^{2}=$ variância fenotípica do parental 1 ; 
$\hat{\sigma}_{\mathrm{P} 2}=$ variância fenotípica do parental 2, e

$\wedge^{2}$

$\hat{\sigma}_{F 1}^{2}=$ variância fenotípica da geração $\mathrm{F}_{1}$.

Com base nas estimativas, foram obtidos os valores do coeficiente de herdabilidade da capacidade embriogênica $\left(\hat{h}^{2}\right)$ e o número de genes $(\eta)$ relacionados à característica (Stansfield, 1983; Ramalho et al., 1989), como segue:

$\hat{h}^{2}=\hat{\sigma}_{\mathrm{A}}^{2} / \hat{\sigma}_{F}^{2}$, em que:

$\hat{h}^{2}=$ coeficiente de herdabilidade;

$\hat{\sigma}_{\mathrm{A}}^{2}=$ variância genética aditiva e

$\hat{\sigma}_{F}^{2}=$ variância fenotípica.

$\eta=\left(\mu_{\mathrm{P}_{1}}-\mu_{\mathrm{P}_{2}}\right)^{2} / 8 \times\left(\hat{\sigma}_{F 2}^{2}-\hat{\sigma}_{\mathrm{E}}^{2}\right)$, em que:

$\eta=$ número de genes;

$\mu_{\mathrm{P}_{1}}$ e $\mu_{\mathrm{P} 2}=$ média dos parentais 1 e 2 , respectivamente; $\lambda^{2}$

$\hat{\sigma}_{F 2}=$ variância fenotípica da geração $\mathrm{F}_{2}$, e

$\hat{\sigma}_{\mathrm{E}}^{2}=$ variância ambiental.

As estimativas entre as diversas gerações foram calculadas pelo teste qui-quadrado por aderência para as gerações $F_{1}, F_{2}$ e retrocruzamentos, sendo comparados os resultados observados com os valores esperados de cada geração. Nas comparações entre as gerações $F_{1}$ e $F_{2}$, foi utilizado o teste qui-quadrado em uma tabela de contingência 2 x 2, de acordo com as recomendações de Snedecor $\&$ Cochran (1989) e Pimentel-Gomes (1990).

\section{Resultados e Discussão}

No cruzamento entre IAS-5 $\left(\mathrm{P}_{1}\right)$ e IAC-6 $\left(\mathrm{P}_{2}\right)$, verifica-se que o parental $\mathrm{P}_{1}$ apresentou média de embriões somáticos superior em relação ao parental não-embriogênico $\left(\mathrm{P}_{2}\right)$ (Tabela 1). Constata-se, ain-

Tabela 1. Médias $(\hat{\mu})$, variâncias $\left(\hat{\sigma}^{2}\right)$, erros padrões das médias (EP), tamanho das amostras (N) e estimativas de parâmetros genéticos dentro do cruzamento entre os parentais IAS-5 $\left(\mathrm{P}_{1}\right)$ e IAC-6 $\left(\mathrm{P}_{2}\right)^{(1)}$.

\begin{tabular}{lcccc}
\hline Geração & $\hat{\mu}$ & $\hat{\sigma^{2}}$ & $\mathrm{EP}$ & $\mathrm{N}$ \\
\hline $\mathrm{P}_{1}$ & 24,75 & 0,19 & 0,05 & 80 \\
$\mathrm{P}_{2}$ & 3,00 & 0,50 & 0,08 & 80 \\
$\mathrm{~F}_{1}$ & 6,25 & 0,19 & 0,10 & 20 \\
$\mathrm{~F}_{2}$ & 18,50 & 2,25 & 0,17 & 80 \\
$\mathrm{RC}_{1} \mathrm{P}_{1}$ & 5,25 & 0,69 & 0,19 & 20 \\
$\mathrm{RC}_{1} \mathrm{P}_{2}$ & 2,25 & 0,69 & 0,20 & 18 \\
\hline Estimativas & $\hat{\sigma}_{A}=3,12$ & $\hat{\sigma}_{E}=0,29$ & $\hat{h}^{2}=0,91$ & $\eta=28,71$ \\
\hline
\end{tabular}

(1) $\hat{\sigma}_{A}$ : estimativa da variância aditiva; $\hat{\sigma}_{E}$ : estimativa da variância ambiental; $\hat{h}^{2}$ : coeficiente de herdabilidade; $\eta$ : estimativa do número de genes; $\chi^{2}: \mathrm{F}_{1} \mathrm{x}$ $\mathrm{E}\left(\mathrm{F}_{1}\right)=2,700^{\text {ns }} ; \mathrm{F}_{2} \times \mathrm{E}\left(\mathrm{F}_{2}\right)=0,070^{\mathrm{ns}} ; \mathrm{F}_{1} \times \mathrm{F}_{2}=0,570^{\mathrm{ns}} ; \mathrm{RC}_{1} \mathrm{P}_{1} \times$ $\mathrm{E}\left(\mathrm{RC}_{1} \mathrm{P}_{1}\right)=0,050^{\text {ns }} ; \mathrm{RC}_{1} \mathrm{P}_{2} \times \mathrm{E}\left(\mathrm{RC}_{1} \mathrm{P}_{2}\right)=0,050^{\text {ns }}$. ns Não-significativo a $5 \%$ de probabilidade. da, que a geração $F_{1}$ possui a média do caráter intermediária à média dos parentais, sugerindo uma ação aditiva para o caráter, segundo Falconer (1989), Ramalho et al. (1989), Vencovsky \& Barriga (1992), Ramalho et al. (1993) e Di Mauro et al. (1995b). Além disso, salienta-se que, quando comparados os valores observados com os esperados entre as gerações $\mathrm{F}_{1}, \mathrm{~F}_{2}, \mathrm{RC}_{1} \mathrm{P}_{1}$ e $\mathrm{RC}_{1} \mathrm{P}_{2}$, como também os valores $F_{1}$ e $F_{2}$, constatou-se que não houve diferença significativa entre os valores, pelo teste qui-quadrado a $5 \%$. O componente aditivo foi de 3,12 e o componente ambiental, como esperado, foi de baixa magnitude $(0,29)$. Nota-se, também, a grande magnitude do coeficiente de herdabilidade $(0,91)$, indicando que essa população é adequada para um processo seletivo visando o desenvolvimento de genótipos com boa capacidade de produção de embriões somáticos. Destaca-se que o número de genes relacionados à característica foi, aproximadamente, de 29, segundo metodologia de Stansfield (1983) e Ramalho et al. (1989).

No cruzamento entre os parentais Paraná $\left(\mathrm{P}_{1}\right)$ e IAS-5 $\left(\mathrm{P}_{2}\right)$, o parental embriogênico $\left(\mathrm{P}_{2}\right)$ apresentou média de embriões somáticos superior à do parental não-embriogênico $\left(\mathrm{P}_{1}\right)$ (Tabela 2$)$. A média da geração $F_{1}$ foi intermediária à média dos parentais, o que sugere que o caráter é governado por genes com ação aditiva. Nas comparações entre os valores observados e esperados entre as diversas gerações, não foram constatadas diferenças significativas pelo quiquadrado, a 5\% de probabilidade, o que reforça a hipótese do envolvimento da ação gênica aditiva no controle da capacidade de produção de embriões somáticos dentro desse cruzamento biparental. Anali-

Tabela 2. Médias $(\hat{\mu})$, variâncias $\left(\hat{\sigma^{2}}\right)$, erros-padrões das médias (EP), tamanho das amostras $(\mathrm{N})$ e estimativas de parâmetros genéticos dentro do cruzamento entre os parentais Paraná $\left(\mathrm{P}_{1}\right)$ e IAS-5 $\left(\mathrm{P}_{2}\right)^{(1)}$.

\begin{tabular}{lrccc}
\hline Geração & $\hat{\mu}$ & $\hat{\sigma}^{2}$ & $\mathrm{EP}$ & $\mathrm{N}$ \\
\hline $\mathrm{P}_{1}$ & 2,25 & 0,69 & 0,09 & 80 \\
$\mathrm{P}_{2}$ & 24,75 & 0,19 & 0,05 & 80 \\
$\mathrm{~F}_{1}$ & 4,00 & 0,50 & 0,16 & 19 \\
$\mathrm{~F}_{2}$ & 13,25 & 3,69 & 0,21 & 80 \\
$\mathrm{RC}_{1} \mathrm{P}_{1}$ & 3,25 & 0,69 & 0,19 & 20 \\
$\mathrm{RC}_{1} \mathrm{P}_{2}$ & 3,00 & 0,50 & 0,16 & 20 \\
\hline Estimativas & $\hat{\sigma}_{A}=6,19$ & $\hat{\sigma}_{E}=0,46$ & $\hat{h}^{2}=0,93$ & $\eta=19,84$ \\
\hline
\end{tabular}

(1) $\hat{\sigma}_{A}$ : estimativa da variância aditiva; $\hat{\sigma}_{E}$ : estimativa da variância ambiental; $\hat{h}^{2}$ : coeficiente de herdabilidade; $\eta$ : estimativa do número de genes; $\chi^{2}: \mathrm{F}_{1} \times \mathrm{E}\left(\mathrm{F}_{1}\right)=0,230^{\text {ns; }} ; \mathrm{F}_{2} \times \mathrm{E}\left(\mathrm{F}_{2}\right)=0,310^{\text {ns; }} ; \mathrm{F}_{1} \times \mathrm{F}_{2}=0,220^{\text {ns }}$, $\mathrm{RC}_{1} \mathrm{P}_{1} \times \mathrm{E}\left(\mathrm{RC}_{1} \mathrm{P}_{1}\right)=0,870^{\text {ns; }} ; \mathrm{RC}_{1} \mathrm{P}_{2} \times \mathrm{E}\left(\mathrm{RC}_{1} \mathrm{P}_{2}\right)=0,870^{\text {ns }}$ ns Não-significativo a $5 \%$ de probabilidade. 
sando-se as variâncias, constatou-se que as variâncias aditiva e ambiental foram maiores que no caso anterior. O coeficiente de herdabilidade, em função dos valores observados na variância aditiva e na ambiental foi de grande magnitude, e possibilitou também o processo seletivo para o desenvolvimento de genótipos de soja embriogênicos. Acresce, ainda, que o número de genes relacionados com a característica foi de 20, o que indica uma poligenia.

Como observado nos casos anteriores, também na população oriunda do cruzamento entre IAC-15 e IAS-5, o caráter capacidade de produção de embriões somáticos revelou-se poligênico e primariamente governado por genes com ação aditiva, conforme os resultados do teste qui-quadrado (Tabela 3). Neste caso, foi observada maior magnitude das variâncias ambiental e aditiva, e isto pode ser explicado pelos maiores valores relacionados com as variâncias fenotípicas das gerações $F_{1}$ e $F_{2}$. Como conseqüência do maior efeito ambiental, o valor estimado do coeficiente de herdabilidade foi superior aos valores estimados relativos aos cruzamentos precedentes, o que sugere que essa população também é adequada para a imposição de um processo seletivo que venha a resultar no desenvolvimento de genótipos de soja embriogênicos. O número de genes relacionados com a característica foi estimado como sendo, aproximadamente, de 12.

Os resultados apresentados na Tabela 4 são oriundos do cruzamento entre os parentais IAS-5 e Paraná,

Tabela 3. Médias $(\hat{\mu})$, variâncias $\left(\hat{\sigma^{2}}\right)$, erros-padrões das médias (EP), tamanho das amostras $(\mathrm{N})$ e estimativas de parâmetros genéticos dentro do cruzamento entre os parentais IAC-15 $\left(\mathrm{P}_{1}\right)$ e IAS-5 $\left(\mathrm{P}_{2}\right)^{(1)}$.

\begin{tabular}{lrccc}
\hline Geração & $\hat{\mu}$ & $\hat{\sigma^{2}}$ & $\mathrm{EP}$ & $\mathrm{N}$ \\
\hline $\mathrm{P}_{1}$ & 3,00 & 0,50 & 0,08 & 80 \\
$\mathrm{P}_{2}$ & 24,75 & 0,19 & 0,05 & 80 \\
$\mathrm{~F}_{1}$ & 4,25 & 1,19 & 0,24 & 20 \\
$\mathrm{~F}_{2}$ & 13,75 & 6,19 & 0,28 & 80 \\
$\mathrm{RC}_{1} \mathrm{P}_{1}$ & 3,00 & 0,50 & 0,18 & 15 \\
$\mathrm{RC}_{1} \mathrm{P}_{2}$ & 6,00 & 0,50 & 0,16 & 20 \\
\hline \multirow{2}{*}{ Estimativas } & $\hat{\sigma}_{A}=11,38$ & $\hat{\sigma}_{E}=0,63$ & $\hat{h}^{2}=0,95$ & $\eta=11,83$
\end{tabular}

(1) $\hat{\sigma}_{A}$ : estimativa da variância aditiva; $\hat{\sigma}_{E}$ : estimativa da variância ambiental; $\hat{h}^{2}$ : coeficiente de herdabilidade; $\eta$ : estimativa do número de genes; $\chi^{2}: \mathrm{F}_{1} \times E\left(\mathrm{~F}_{1}\right)=0,190^{\text {ns }} ; \mathrm{F}_{2} \times \mathrm{E}\left(\mathrm{F}_{2}\right)=0,270^{\text {nss }} ; \mathrm{F}_{1} \times \mathrm{F}_{2}=0,180^{\text {ns }} ; \mathrm{RC}_{1} \mathrm{P}_{1} \times \mathrm{E}$ $\left(\mathrm{RC}_{1} \mathrm{P}_{1}\right)=1,430^{\text {ns. }}, \mathrm{RC}_{1} \mathrm{P}_{2} \times \mathrm{E}\left(\mathrm{RC}_{1} \mathrm{P}_{2}\right)=0,400^{\text {ns. ns }}$. Não-significativo a $5 \%$ de probabilidade.

Pesq. agropec. bras., Brasília, v. 36, n. 11, p. 1381-1385, nov. 2001
Tabela 4. Médias $(\hat{\mu})$, variâncias $\left(\hat{\sigma^{2}}\right)$, erros-padrões das médias (EP), tamanho das amostras $(\mathrm{N})$ e estimativas de parâmetros genéticos dentro do cruzamento entre os parentais IAS-5 $\left(\mathrm{P}_{1}\right)$ e Paraná $\left(\mathrm{P}_{2}\right)^{(1)}$.

\begin{tabular}{lrccc}
\hline Geração & $\hat{\mu}$ & $\hat{\sigma^{2}}$ & $\mathrm{EP}$ & $\mathrm{N}$ \\
\hline $\mathrm{P}_{1}$ & 24,75 & 0,19 & 0,05 & 80 \\
$\mathrm{P}_{2}$ & 2,25 & 0,69 & 0,09 & 80 \\
$\mathrm{~F}_{1}$ & 3,50 & 0,25 & 0,11 & 20 \\
$\mathrm{~F}_{2}$ & 13,50 & 3,25 & 0,20 & 80 \\
$\mathrm{RC}_{1} \mathrm{P}_{1}$ & 5,00 & 0,50 & 0,17 & 18 \\
$\mathrm{RC}_{1} \mathrm{P}_{2}$ & 0,25 & 0,19 & 0,17 & 16 \\
\hline \multirow{2}{*}{ Estimativas } & $\hat{\sigma}_{A}=5,81$ & $\hat{\sigma}_{E}=0,38$ & $\hat{h}^{2}=0,94$ & $\eta=21,09$ \\
\hline
\end{tabular}

(1) $\hat{\sigma}_{A}$ : estimativa da variância aditiva; $\hat{\sigma}_{E}$ : estimativa da variância ambiental; $\hat{h}^{2}$ : coeficiente de herdabilidade; $\eta$ : estimativa do número de genes; $\chi^{2}: F_{1} \times E\left(F_{1}\right)=0,005^{\text {ns }} ; F_{2} \times E\left(F_{2}\right)=0,050^{\text {ns. }} ; F_{1} \times F_{2}=0,004^{\text {ns }}$ $\mathrm{RC}_{1} \mathrm{P}_{1} \times \quad \mathrm{E}\left(\mathrm{RC}_{1} \mathrm{P}_{1}\right)=0,170^{\text {ns; }} ; \quad \mathrm{RC}_{1} \mathrm{P}_{2} \times \quad \mathrm{E}\left(\mathrm{RC}_{1} \mathrm{P}_{2}\right)=1,220^{\text {ns }}$ ns Não-significativo a $5 \%$ de probabilidade.

e portanto, recíprocos em relação aos resultados apresentados na Tabela 2. Também neste caso constatouse aditividade e poligenia relacionadas com a capacidade de produção de embriões somáticos. Interessante é a comparação dos resultados encontrados da média de embriões somáticos produzidos pelas gerações $F_{1}$ e $F_{2}$ desses dois cruzamentos. Nota-se que estas gerações são muito semelhantes, o que permite inferir que muito provavelmente não existe efeito materno na capacidade de produção de embriões somáticos em soja, quando se considera o referido cruzamento.

\section{Conclusões}

1. A média da geração $F_{1}$ de todos os cruzamentos revela-se próxima à média entre os parentais dos respectivos cruzamentos.

2. O número de genes relacionados com a característica estudada é, em média, de 20, variando de 12 a 29 genes nos cruzamentos estudados.

3. A análise do cruzamento recíproco não evidencia a existência de efeito materno na capacidade de produção de embriões somáticos da cultivar IAS-5.

\section{Referências}

ALLARD, R. W. Princípios do melhoramento genético das plantas. Rio de Janeiro: E. Blucher, 1974. p. 81-87.

BODANESE-ZANETTINI, M. H.; ORTOLAN, M. G. S.; $\mathrm{HU}, \mathrm{C}$. Somatic embryoid induction from Brazilian 
soybean cultivars. Revista Brasileira de Genética, Ribeirão Preto, v. 16, n. 1, p. 129-134, 1993.

DI MAURO, A. O.; NÓBREGA, J. C.; COLLINS, G. B. Screening soybean genotypes regarding to their ability to produce somatic embryos. Científica, Jaboticabal, v. 23, p. 218-223, 1995a.

DI MAURO, A. O.; PFEIFFER, T.; COLLINS, G. B. Inheritance of soybean susceptibility to Agrobacterium tumefaciens and its relationship to transformation. Crop Science, Madison, v. 35, p. 1152-1156, 1995 b.

DI MAURO, A. O.; PFEIFFER, T.; COLLINS, G. B.; VIEIRA, R. D. Estudo da interação entre genótipos e posições de explantes de soja (Glycine max (L.) Merrill) no meio de cultura para indução da embriogênese somática Científica, Jaboticabal, v. 22, n. 1, p. 133-144, 1994.

FALCONER, D. S. Introduction to quantitative genetics. 3. ed. New York: Longman, 1989. p. 83-86; 102-110.

FEHR, W. R. Principles of cultivar development. 2. ed New York: McGraw-Hill, 1987. v. 1, p. 80-86.
HIROMOTO, D. M.; VELLO, N. A. The genetic base of Brazilian soybean (Glycine max (L.) Merrill) cultivars. Revista Brasileira de Genética, Ribeirão Preto, v. 9, p. 295-306, 1986.

KILEN, T. C. Inheritance of a long terminal raceme in soybean. Crop Science, Madison, v. 29, p. 966-968,1989. PIMENTEL-GOMES, F. Curso de Estatística Experimental. 13. ed. São Paulo: Nobel, 1990. p. 287-298.

RAMALHO, M. A. P.; SANTOS, J. B. dos; PINTO, C. B Genética na agropecuária. São Paulo: Globo/Fundação de Apoio ao Ensino, Pesquisa e Extensão, 1989. p. 199-229.

RAMALHO, M. A. P.; SANTOS, J. B. dos; ZIMMERMANN, M. J. O. Genética quantitativa em plantas autógamas. Goiânia: UFG, 1993. p. 29-75.

SNEDECOR, G. W.; COCHRAN, W. G. Statistical methods. 8. ed. Ames: Iowa State University Press, 1989. p. 107-130.

STANSFIELD, W. D. Genetics. 2. ed. New York: McGraw-Hill Book, 1983. p. 221-244.

VENCOVSKY, R.; BARRIGA, P. Genética biométrica no fitomelhoramento. Ribeirão Preto: Sociedade Brasileira de Genética, 1992. p. 158-227. 